\title{
EVALUATION OF THERMAL PROPERTIES OF CERTAIN FLAME-RETARDANT FABRICS MODIFIED WITH A MAGNETRON SPUTTERING METHOD
}

\author{
Pamela Miśkiewicz ${ }^{1, *}$, Magdalena Tokarska ${ }^{1}$, Iwona Frydrych $^{1,2}$, Marcin Makówka $^{3}$ \\ 1 Faculty of Material Technologies and Textile Design, Institute of Architecture of Textiles, Lodz University of Technology, \\ 116 Zeromskiego St., 90-924 Lodz, Poland \\ 2 Department of Personal Protective Equipment, Central Institute for Labour Protection—National Research Institute, \\ 48 Wierzbowa St., 90-133 Lodz, Poland \\ 3 Faculty of Mechanical Engineering, Institute of Materials Science and Engineering, Lodz University of Technology, \\ 1/15 Stefanowskiego St., 90-924 Lodz, Poland \\ *Corresponding author. E-mail: pamela_miskiewicz@wp.pl
}

\begin{abstract}
:
The article presents the modification of flame-retardant fabric surfaces made of basalt, Nomex®, and cotton fabric to improve their selected thermal comfort properties. The modification consisted of depositing on the fabric surface by magnetron sputtering the metal (aluminum) and ceramic (zirconium (IV) oxide) coatings with a thickness of 1 $\mu \mathrm{m}$ and $5 \mu \mathrm{m}$. Flame-retardant fabrics have been chosen because of the desire to apply them to gloves intended for the use in hot-work environments. The article presents the results of testing reference samples and their modifications, which were subjected to the test of resistance to contact heat for contact temperatures of $100^{\circ} \mathrm{C}$ and $250^{\circ} \mathrm{C}$, resistance to thermal radiation and examined their selected thermal comfort parameters, i.e., the thermal conductivity coefficient and heat absorption coefficient. Almost the $1^{\text {st }}$ efficiency level for contact heat was reached for basalt fabric coated with zirconium (IV) oxide with a thickness of $5 \mu \mathrm{m}$. The $1^{\text {st }}$ level of protection against heat radiation was obtained for all reference and modified samples. Based on the Kruskal-Wallis test, it was noticed that a significant change in parameter values is caused by the modification with $5 \mu \mathrm{m}$ thick coating.
\end{abstract}

\section{Keywords:}

Basalt fabric, flame-retardant fabric, magnetron sputtering, thermal properties

\section{Introduction}

Nowadays, scientists are striving to combine various scientific disciplines to obtain an innovative product with new properties, or a product with improved properties. The process of physical vapor deposition (PVD) relying on the coating formed on a selected substrate by the physical application of atoms, molecules, or ions of certain chemical compounds is already used to modify textile materials (fabrics, nonwovens, and knitted fabrics) to improve their specific properties [1, 2].

In the case of technical applications, there is a tendency to produce textile materials characterized by innovative, specially designed surface features, which make it possible to apply them in both industry and science. Researchers modify textiles differently with the PVD process to improve their shielding properties, e.g., using a cathodic sputtering method to obtain ultrathin metallic coatings on selected textile substrates [3]. Copper was sprayed onto the polyester, viscose, and polypropylene nonwovens. The nonwovens selected for testing were characterized by low surface mass values due to their use as wallpaper. The samples produced had a good screening efficiency, and the best was obtained for the copper-coated polypropylene nonwoven. Besides, it was found that the basic condition for obtaining a good quality material is to produce the most continuous metal coating on the surface of nonwovens. Another example is the modification of textile materials by methods of the PVD process to obtain electroconductive materials and use them in textronics $[4,5]$. Especially, the analysis of thermographic image of thin metal layers as a part of working textronic system was performed. Research on the functionalization of nonwovens modified by sputtering aluminum on their surface was also carried out [6]. Aluminum was deposited on the commercial surface of polyester nonwoven fabric by using the magnetron sputtering method. The electrical resistance of sputtered aluminum was significantly reduced. However, the deposited aluminum coating had a significant effect on the nonwoven surface. It was found that the obtained nonwoven materials can be used in the production of conductive screens. The PVD process used to modify textile materials is also used to obtain antibacterial materials [7]. The high-power pulsed magnetron sputtering method deposited a silver coating on the surface of the polyester fabric to obtain an even coverage of fabric and good adhesion of coating to the fabric substrate. The coating obtained by the high-power pulsed magnetron sputtering was characterized by much better antimicrobial effectiveness, and the chosen method can be used to produce fabrics exhibiting antibacterial properties. 
Some publications can be found for modifying textile materials with the PVD process to improve thermal properties. An aluminum (Al) coating was deposited on the surface of aramid fabric, a two-layered coating containing aluminum with silicon dioxide and a three-layered coating containing silicon dioxide/ aluminum/silicon dioxide [8]. The DC magnetron sputtering technique was used to deposit the metal coating (aluminum), while the AC magnetron sputtering was used for the nonmetallic coating. Continuous coatings were obtained on the fabric surface for all three embedded structures. Resistance to thermal radiation has improved for all types of coatings. The value of $\mathrm{SiO}_{2} / \mathrm{Al} / \mathrm{SiO}_{2}$ reflection coefficient was $64.97 \%$, for $\mathrm{SiO}_{2} / \mathrm{Al}$ was $57.38 \%$, and for a single $\mathrm{Al}$ was $51.59 \%$, respectively. Another example is the study of heat transfer in textile materials sputtered with the aluminum [9]. Four textile substrates were selected for testing: polyester, nylon, cotton blend with 50/50 polyester, and polyurethane with the shape memory. Aluminum was sprayed on one side only. It was found that reference (unmodified) fabrics and fabrics modified with the aluminum coating differed in the thermal conductivity and thickness and showed different heat emissivity. To test heat transfer properties, samples were selected, on which aluminum was deposited for $10 \mathrm{~min}$. Then it was observed that the heat transfer coefficient of aluminum coating increased with its thickness. The lowest heat transfer coefficient was recorded for the cotton/polyester blend (50/50). The effects of silica $\left(\mathrm{SiO}_{2}\right)$ and zinc oxide $(\mathrm{ZnO})$ on the flame-retardant properties of cotton and polyester cotton were investigated [10]. The solgel process was used for the fabric surface modification. It was found that the flame retardancy was more improved with the addition of silica nanoparticles than zinc oxide for both samples.

Research on a direct modification of basalt fabric surface to improve its thermal properties was conducted [11-13]. The researchers would like to use the modified fabric in gloves that protect against high temperatures and hot factors. Until then, the basalt fabric was modified as a result of magnetron sputtering method. Chromium, aluminum, and zirconia coatings in various thicknesses were produced on the fabric surface. Due to the intended use of gloves in the hot-work environment, the modified fabric was subjected to tests on the contact heat resistance for contact temperatures of $100^{\circ} \mathrm{C}$ and $250^{\circ} \mathrm{C}$ and the resistance to radiation heat. The above-mentioned studies were not satisfactory for the authors because they strive to obtain resistance to contact heat for the contact temperature of $250^{\circ} \mathrm{C}$, while wanting to obtain the best results for the resistance to thermal radiation.

In the article, definitely different textile materials were chosen for testing. Basalt is an entirely new class of materials, which could successfully replace the most kinds of steel and other materials. Nomex ${ }^{\circledR}$ fabric has flame-resistant properties, and cotton fabric has the flame-retardant finishing. All the fabrics have protective properties. To use them in gloves that protect against high temperatures and hot factors, the surface modification is needed. The PVD method, i.e., reactive magnetron sputtering (RMS) method was chosen [14]. The task of coatings obtained by PVD and especially by RMS method depending on their purpose is primarily not only to deteriorate the mechanical properties of the substrate but also to improve anticorrosion and tribological properties. One of the most important properties of coatings obtained with the help of PVD processes is their adhesion to the substrate. If the adhesion is incorrect, the functionality of the coating may be lost. On the surfaces of selected fabrics, one-sided coating of aluminum (Al) or zirconium (IV) oxide $\left(\mathrm{ZrO}_{2}\right)$ was made with a thickness of $1 \mu \mathrm{m}$ and $5 \mu \mathrm{m}$. The samples were tested for protective and thermal comfort properties. The obtained results were compared and the statistical analysis of selected parameters was carried out.

\section{Materials}

Twill weave woven fabrics were selected as a textile substrate to the surface modification: basalt fabric, Nomex® Comfort $E$ fabric, and cotton fabric with the flame-retardant finishing. The characteristics of selected fabrics are given in Table 1.

All the fabrics are used in systems of materials intended for the personal protective equipment in a hot-work environment. Basalt fibers have a low thermal conductivity and they are flame-retardant. Therefore, fabrics made of them are good for the protection against fire and heat [15]. Nomex $₫$ fibers provide the effective protection against flame and high temperature [16]. Cotton flame-retardant fabric protects the workers from heat and flame, along with the soft hand feel [17]. Using an Olympus SZX10 stereo microscope and Olympus Stream Start software, images of woven fabrics were captured at a total visual magnification of $9.5 x$ and are presented in Table 2.

Table 1. Characteristics of selected fabrics

\begin{tabular}{|c|c|c|c|c|c|}
\hline Sample & Woven fabric & $\begin{array}{c}\text { Raw material } \\
\text { composition }\end{array}$ & Manufacturer & Thickness, mm & Surface mass, $\mathbf{m} / \mathbf{m}^{2}$ \\
\hline $\mathrm{B}$ & Basalt fabric & $100 \%$ basalt fibers & $\begin{array}{c}\text { Basaltex, Šmperk, } \\
\text { Czech Republic }\end{array}$ & 0.55 & 398 \\
\hline $\mathrm{N}$ & Nomex® fabric & $\begin{array}{c}93 \% \text { m-aramid, } \\
5 \% \text { p-aramid, } \\
2 \% \text { antistatic fibers P140 }\end{array}$ & $\begin{array}{c}\text { DuPont, } \\
\text { Wilmington, USA }\end{array}$ & 0.37 \\
\hline C & Cotton fabric & $\begin{array}{c}100 \% \text { cotton fibers, fabric } \\
\text { with the flame-retardant } \\
\text { finishing }\end{array}$ & $\begin{array}{c}\text { XinXiang YuLong } \\
\text { Textile, Xinxiang, } \\
\text { China }\end{array}$ & 0.66 & 376 \\
\hline
\end{tabular}


Table 2. Images of fabrics

\begin{tabular}{|c|c|c|c|}
\hline Basalt fabric & Nomex ${ }^{\circ}$ fabric & Cotton fabric \\
\hline & & & \\
\hline
\end{tabular}

All the fabrics were modified with an aluminum coating of the thickness of $1 \mu \mathrm{m}$ and $5 \mu \mathrm{m}$ and with zirconium (IV) oxide coating of the same thickness values. The designations of the modified sample variants are shown in Table 3.

\section{Methods}

\subsection{Magnetron sputtering}

The magnetron sputtering method uses a glow discharge realized at the reduced pressure and in the presence of two mutually perpendicular fields: magnetic and electric fields. The emitted electrons move along the helical path in a direction perpendicular to the directions of both fields along the magnetic field force lines. The intersection of fields leads to the closing of electrons in the example zone. Electrons moving in the example zone ionize the gas atmosphere. A strong electric field accelerates positively charged ions toward the cathode, which, when hitting the cathode surface, causes its sputtering. Magnetron sputtering can be carried out both in an inert atmosphere, which results in the production of metallic coatings, as well as in an atmosphere, a mixture of reactive gases, which results in the production of coatings that are compounds, e.g., metals with nitrogen, oxygen, or carbon.

Aluminum and zirconium (IV) oxide with a thickness of $1 \mu \mathrm{m}$ and $5 \mu \mathrm{m}$ were deposited on basalt, Nomex®, and cotton fabrics. Coatings were deposited in the B-90 vacuum chamber (from Hoch-Vacuum, Dresden) by magnetron sputtering on one side of the fabric. Two independent planar magnetrons WK100 (from Dora POWER SYSTEMS) fitted with circular targets $\varnothing 100 \times 10 \mathrm{~mm}$ were used for the coating deposition. Two targets were made from pure $\mathrm{Al}(4 \mathrm{~N})$ for deposition of $\mathrm{Al}$ coating and two targets from pure zirconium $(3.5 \mathrm{~N})$ for deposition of $\mathrm{ZrO}_{2}$ coatings. Magnetrons were fixed facing each other in a horizontal plane and on the same axis. All substrates before mounting them in the vacuum chamber were cleaned by isopropyl alcohol. After mounting the specimens in the specimens holder, the vacuum chamber was closed and pumped down to a pressure of $2 \times 10^{-3} \mathrm{~Pa}$. After achieving an appropriate residual pressure, deposition process was carried out according to the scheme described as follows (detailed parameters are shown in Table 4):

1. Specimens holder was put in the motion around the vertical axis at a value of the rotation speed $8 \mathrm{rpm}$.

Table 3. Designations of modified fabrics

\begin{tabular}{|c|c|c|c|c|}
\hline Symbol & BA1 & BA5 & BZ1 & BZ5 \\
\hline Description & $\begin{array}{l}\text { Basalt fabric modified } \\
\text { with Al coating of the } \\
\text { thickness of } 1 \mu \mathrm{m}\end{array}$ & $\begin{array}{l}\text { Basalt fabric modified } \\
\text { with Al coating of the } \\
\text { thickness of } 5 \mu \mathrm{m}\end{array}$ & $\begin{array}{l}\text { Basalt fabric modified } \\
\text { with } \mathrm{ZrO}_{2} \text { coating of the } \\
\text { thickness of } 1 \mu \mathrm{m}\end{array}$ & $\begin{array}{l}\text { Basalt fabric modified } \\
\text { with } \mathrm{ZrO}_{2} \text { coating of the } \\
\text { thickness of } 5 \mu \mathrm{m}\end{array}$ \\
\hline Symbol & NA1 & NA5 & NZ1 & NZ5 \\
\hline Description & $\begin{array}{l}\text { Nomex@ fabric modified } \\
\text { with Al coating of the } \\
\text { thickness of } 1 \mu \mathrm{m}\end{array}$ & $\begin{array}{l}\text { Nomex® fabric modified } \\
\text { with Al coating of the } \\
\text { thickness of } 5 \mu \mathrm{m}\end{array}$ & $\begin{array}{l}\text { Nomex }{ }^{\circledR} \text { fabric modified } \\
\text { with } \mathrm{ZrO}_{2} \text { coating of the } \\
\text { thickness of } 1 \mu \mathrm{m}\end{array}$ & $\begin{array}{l}\text { Nomex@ fabric modified } \\
\text { with } \mathrm{ZrO}_{2} \text { coating of the } \\
\text { thickness of } 5 \mu \mathrm{m}\end{array}$ \\
\hline Symbol & CA1 & CA5 & CZ1 & CZ5 \\
\hline Description & $\begin{array}{l}\text { Cotton fabric modified } \\
\text { with Al coating of the } \\
\text { thickness of } 1 \mu \mathrm{m}\end{array}$ & $\begin{array}{l}\text { Cotton fabric modified } \\
\text { with Al coating of the } \\
\text { thickness of } 5 \mu \mathrm{m}\end{array}$ & $\begin{array}{l}\text { Cotton fabric modified } \\
\text { with } \mathrm{ZrO}_{2} \text { coating of the } \\
\text { thickness of } 1 \mu \mathrm{m}\end{array}$ & $\begin{array}{l}\text { Cotton fabric modified } \\
\text { with } \mathrm{ZrO}_{2} \text { coating of the } \\
\text { thickness of } 5 \mu \mathrm{m}\end{array}$ \\
\hline
\end{tabular}


2. Argon (Ar) pressure in the vacuum chamber was stabilized at $\operatorname{Ar}(5 \mathrm{~N})$ flow $25 \mathrm{sccm}$.

3. Appropriate magnetron power sources were switched on and pure $\mathrm{Al}$ coating or pure $\mathrm{Zr}$ interlayer was deposited. For reactive processes of deposition of $\mathrm{ZrO}_{2}$ coating, after the third minute of deposition of pure $\mathrm{Zr}$, pure $\mathrm{O}_{2}(5 \mathrm{~N})$ was introduced into the vacuum chamber.

After deposition, all power sources were switched off simultaneously and gas valves were closed.

\subsection{Resistance to contact heat}

The basic standard, which defines the requirements and test methods for gloves protecting against hot agents occurring in various forms, i.e., the flame, contact heat, convective heat, radiation heat, small splashes of molten metal, and large amounts of liquid metal, is standard EN 407:2004 [18]. This standard describes, using which testing methods the protective gloves should be tested and references to subsequent standards describing these testing methods are indicated. The standard ISO 12127-1:2016 [19] is recommended to determine the contact heat resistance of fabric reference samples and modified samples. The measurement is performed by subjecting the sample, which is placed on a calorimeter to contact a heating cylinder and heated to the temperature of $100^{\circ} \mathrm{C}$ to $500^{\circ} \mathrm{C}$. When measuring contact heat, the threshold time $t_{t}$ is measured, i.e., the time from the first contact with the heating cylinder until the calorimeter temperature rises by $10^{\circ} \mathrm{C}$ compared with the initial value. For the test of resistance to contact heat, three samples with a diameter of $8 \mathrm{~cm}$ should be prepared which $24 \mathrm{~h}$ before the measurement should be acclimatized under normal climate conditions: temperature $20^{\circ} \mathrm{C} \pm 2^{\circ} \mathrm{C}$ and the relative humidity $65 \% \pm 5 \%$.

For protective gloves, the measurement is made on three samples. The arithmetic mean of three measurements should be calculated, and the result obtained is the final result of threshold time based on which gloves are classified into appropriate level of effectiveness.

Tests of resistance to contact heat are carried out on an OTItype device for testing thermal comfort. For resistance to contact heat, four efficiency levels have been determined in accordance with EN 407:2004 [18], for which gloves should be classified. Due to tests of resistance to contact heat for four contact temperatures: $100^{\circ} \mathrm{C}, 250^{\circ} \mathrm{C}, 350^{\circ} \mathrm{C}$, and $500^{\circ} \mathrm{C}$, we distinguish four levels of effectiveness. The chosen level of efficiency is achieved for all temperatures, when the sample subjected to the test reaches a threshold temperature in time $t_{t} \geq 15.0 \mathrm{~s}$ under the influence of specified temperature in the range $100^{\circ} \mathrm{C}-500^{\circ} \mathrm{C}$.

\subsection{Resistance to radiant heat}

The radiation resistance test was carried out according to the method described in the ISO 6942:2005 [20]. The course of test consists of subjecting the sample placed on an appropriate holder to thermal radiation for a set time. For protective gloves, the time at which the calorimeter increases by $24^{\circ} \mathrm{C}$ is recorded. The value obtained is defined as the thermal radiation transfer coefficient $t_{24}$. The measurement is made for two samples. The arithmetic mean is calculated from the two heat transfer time periods $t_{24}$. The determined value is called $R \mathrm{RTI}_{24}$ coefficient and is taken as the result. The radiant heat transfer coefficient, $\mathrm{RHTI}_{24}$, is the time of a $24^{\circ} \mathrm{C}$ increase in the calorimeter temperature. Radiant heat resistance tests were carried out at the level of thermal radiation with a flux density of $20 \mathrm{~kW} / \mathrm{m}^{2}$. Based on the obtained value of the $\mathrm{RHTI}_{24}$ coefficient, gloves are classified into one of four levels of effectiveness according to EN 407:2004 [18].

\subsection{Thermal comfort properties}

To assess the thermal comfort properties of fabrics, two parameters were chosen. The first one is the thermal conductivity coefficient $\lambda$, a measure of material ability to conduct heat. The parameter specifies the amount of heat per unit area perpendicular to the direction of heat flux, per unit of temperature gradient, and per unit of time. The thermal conductivity coefficient $\lambda$ is expressed in $\mathrm{Wm}^{-1} \mathrm{~K}^{-1}$. The second one is the heat absorption coefficient $b$. The parameter determines the surface property resulting in the sensation during the contact between the human skin and the material. The heat absorption coefficient $b$ is expressed in $\mathrm{Wm}^{2} \mathrm{~s}^{1 / 2} \mathrm{~K}^{-1}$.

The parameters of reference and coated samples were made on the Alambeta device from Sensora [21, 22]. The device allows the registration of heat flux flowing through the tested textile material that is located between two plates. As a result of contact of the sample with these plates, a temperature gradient is created between both external surfaces of tested textile material. This gradient occurs as a result of heating the

Table 4. Parameters of magnetron sputtering carried out

\begin{tabular}{|c|c|c|c|c|c|c|c|}
\hline Coating & $\begin{array}{c}\text { Assumed } \\
\text { thickness, } \\
\mathbf{m m}\end{array}$ & $\begin{array}{c}\text { Deposition } \\
\text { time, min }\end{array}$ & $\begin{array}{c}\text { Residual } \\
\text { pressure before } \\
\text { deposition, Pa }\end{array}$ & $\begin{array}{c}\text { Flow of Ar, } \\
\text { sccm }\end{array}$ & $\begin{array}{c}\text { Flow of } \mathbf{O}_{2}, \\
\text { sccm }\end{array}$ & $\begin{array}{c}\text { Pressure } \\
\text { during } \\
\text { deposition, Pa }\end{array}$ & $\begin{array}{c}\text { Power on } \\
\text { magnetrons, } \\
\mathbf{k W}\end{array}$ \\
\hline $\mathrm{Al}$ & 1 & 28 & $\sim 2 \times 10^{-3}$ & 25 & - & $3.7-3.8 \times 10^{-1}$ & $2 \times 1.0(\mathrm{Al})$ \\
\hline $\mathrm{Al}$ & 5 & 140 & $\sim 2 \times 10^{-3}$ & 25 & - & $3.7-3.8 \times 10^{-1}$ & $2 \times 1.0(\mathrm{Al})$ \\
\hline $\mathrm{ZrO}_{2}$ & 1 & 35 & $\sim 2 \times 10^{-3}$ & 25 & $12-13$ & $3.8-4.0 \times 10^{-1}$ & $2 \times 1.5(\mathrm{Zr})$ \\
\hline $\mathrm{ZrO}_{2}$ & 5 & 175 & $\sim 2 \times 10^{-3}$ & 25 & $12-13$ & $3.8-4.0 \times 10^{-1}$ & $2 \times 1.5(\mathrm{Zr})$ \\
\hline
\end{tabular}


upper plate to the temperature of $35^{\circ} \mathrm{C}$ and maintaining the temperature of lower plate at $20^{\circ} \mathrm{C}$ at certain constant ambient conditions such as relative humidity, temperature, and airflow rate. Determination of the heat flux density is made as a result of measuring the power of electrical energy to be supplied to maintain the constant temperature of the upper plate. The plates adhere to the tested sample under $200 \mathrm{~Pa} \pm 10 \%$ pressure. The study was conducted in normal climate conditions.

Testing the protective properties the heat flowing from the outside to the inside is examined, while in the case of comfort properties the heat flow from the inside to the outside is examined.

\section{Results and discussion}

Research results of resistance to contact heat of unmodified and modified fabrics expressed by the thermal radiation transfer coefficient $t_{t}$, are presented in Figure 1. Two contact temperatures were chosen out of four according to the standard ISO 12127-1:2016 [19] were determined: first level for $100^{\circ} \mathrm{C}$ and second level for $250^{\circ} \mathrm{C}$.

The highest resistance to contact heat for the contact temperature of $100^{\circ} \mathrm{C}$ was obtained for the basalt fabric (BZ5) with the flame-retardant coating with zirconia with a thickness of $5 \mu \mathrm{m}$ and thermal radiation transfer coefficient equals to $14.9 \mathrm{~s}$. This is due to the fact that the thermal conductivity coefficient for $\mathrm{ZnO}_{2}$ is much smaller than the coefficient for Al. Therefore, almost first efficiency level was reached for the sample. For modified fabrics, the lowest resistance to $100^{\circ} \mathrm{C}$ was achieved for the unmodified basalt fabric $(B)\left(t_{t}=10.8 \mathrm{~s}\right)$ and basalt fabric (BA1) coated with aluminum $1 \mu \mathrm{m}\left(t_{t}=11.0 \mathrm{~s}\right)$.

It was observed that for the contact temperature of $100^{\circ} \mathrm{C}$, as the coating thickness increases, the threshold time value also increases. Modification with metal and ceramics allowed the observation of different values of tested parameter. The higher resistance to contact heat indicated fabric samples that were modified with zirconia.

In the case of contact heat resistance for the contact temperature of $250^{\circ} \mathrm{C}$, the highest value of threshold time

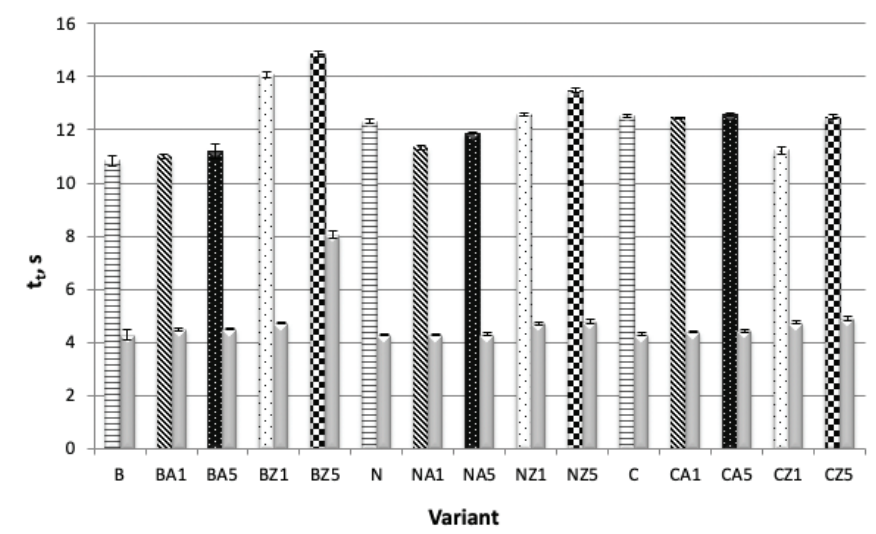

Figure 1. Comparison of contact heat resistance values for all tested fabrics $\left(100^{\circ} \mathrm{C}\right.$-the texture pattern bars; $250^{\circ} \mathrm{C}$-the smooth bars). was obtained for the basalt fabric (BZ5) modified with zirconia with the thickness of $5 \mu \mathrm{m}$ and $t_{t}=8.1 \mathrm{~s}$. None of the fabrics achieved second level of effectiveness of protection against contact heat. Values of threshold time were much below $15.0 \mathrm{~s}$ for the contact temperature equals to $250^{\circ} \mathrm{C}$.

Research results of resistance to radiant heat of unmodified and modified fabrics expressed by the radiant heat transfer coefficient $\mathrm{RHTI}_{24}$ are presented in Figure 2.

In the case of heat radiative resistance test for all reference and modified samples, the first level of protection efficiency was obtained. The second level of protection against heat radiation was achieved for the modified fabrics: basalt (BA1, BA5) and Nomex® (NA1, NA5) as well as for cotton with the flame-retardant finishing (CA5). This is due to the fact that the Al coating reflects light more than the matt $\mathrm{ZnO}_{2}$ coating. Thicker coverage of aluminum reference samples increased the $\mathrm{RHTI}_{24}$ value, resulting in increased protection time against heat radiation. The zirconium (IV) oxide coating, due to its dark brown color, both concerning the basalt (BZ1, BZ5), Nomex® (NZ1, NZ5), and cotton fabrics (CZ1, CZ5), deteriorated their resistance to radiation, because the modifications of zirconia showed worse results compared with reference samples $B, N$, and $\mathrm{C}$, respectively.

Thermal comfort parameters such as the thermal conductivity coefficient $\lambda$ and the heat absorptivity coefficient $b$ are determined for both sides of sample. In the case of coefficient $\lambda$, the modified side of fabric was taken into account. It is assumed that the modified side should protect the user against high temperatures and hot factors. The unmodified side may have contact with the skin provided that it does not cause irritation. In the case of coefficient $b$, the unmodified side of the fabric was considered. The unmodified side being an internal part of protective clothing has a direct contact with the user skin.

Research results from the Alambeta device are presented in Table 5

The thermal conductivity coefficient $\lambda$ is in the range of $38.19 \times 10^{-3}$ to $55.90 \times 10^{-3} \mathrm{Wm}^{-1} \mathrm{~K}^{-1}$. Generally, an upward trend in the thermal conductivity coefficient has been observed for

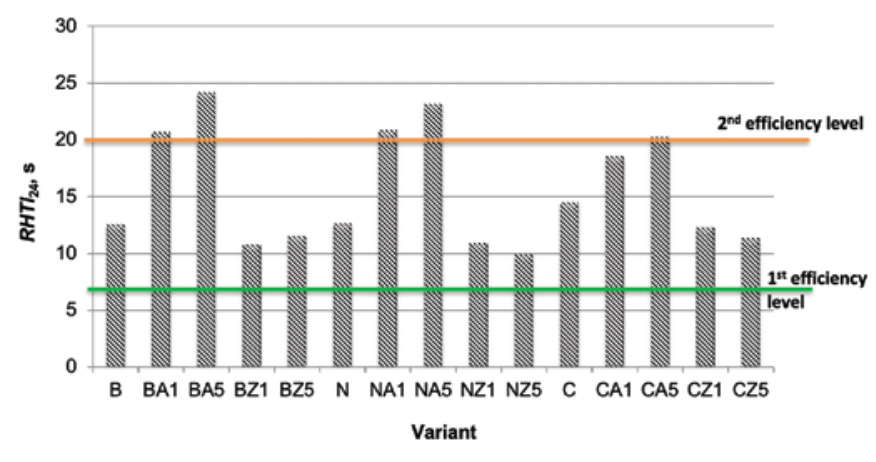

Figure 2. Comparison of radiant heat resistance for all tested fabrics. 
Table 5. Thermal comfort parameters of fabrics

\begin{tabular}{|c|c|c|c|c|c|}
\hline & B & BA1 & BA5 & BZ1 & BZ5 \\
\hline$\lambda, 10^{-3}, \mathrm{Wm}^{-1} \mathrm{~K}^{-1}$ & 38.19 & 45.32 & 46.71 & 40.96 & 43.99 \\
\hline$b, \mathrm{Wm}^{2} \mathrm{~s}^{1 / 2} \mathrm{~K}^{-1}$ & 158.7 & 155.5 & 174.7 & 157.7 & 157.0 \\
\hline & $\mathbf{N}$ & $\mathrm{NA1}$ & $\mathrm{NA5}$ & $\mathrm{NZ1}$ & $\mathbf{N Z 5}$ \\
\hline$\lambda, 10^{-3}, \mathrm{Wm}^{-1} \mathrm{~K}^{-1}$ & 43.34 & 48.71 & 52.68 & 46.54 & 47.01 \\
\hline$b, \mathrm{Wm}^{2} \mathrm{~s}^{1 / 2} \mathrm{~K}^{-1}$ & 147.5 & 193.4 & 179.5 & 171.1 & 174.6 \\
\hline & $\mathbf{C}$ & $\mathbf{C A 1}$ & $\mathbf{C A 5}$ & $\mathbf{C Z 1}$ & $\mathbf{C Z 5}$ \\
\hline$\lambda, 10^{-3}, \mathrm{Wm}^{-1} \mathrm{~K}^{-1}$ & 46.20 & 50.31 & 55.90 & 46.65 & 49.04 \\
\hline$b, \mathrm{Wm}^{2} \mathrm{~s}^{1 / 2} \mathrm{~K}^{-1}$ & 154.0 & 178.5 & 183.4 & 190.3 & 186.1 \\
\hline
\end{tabular}

modified fabrics compared with unmodified ones regardless of the type of coverage. The applied coating caused pores to clog, which resulted in an increase in the coefficient. Lowest conductivity value was achieved for unmodified basalt fabric (B), while the highest value of thermal conductivity was obtained for the cotton fabric with the flame-retardant finishing for $5 \mu \mathrm{m}$ thick aluminum modification (CA5). It was noticed that fabrics coated with zirconium (IV) oxide have a lower coefficient $\lambda$ compared with fabrics coated with the aluminum. The lower the value of thermal conductivity, the better the thermal comfort properties, and therefore the better the comfort.

The heat absorption coefficient $b$ is in the range of 147.5193.4 $\mathrm{Wm}^{2} \mathrm{~s}^{1 / 2} \mathrm{~K}^{-1}$. The higher value of thermal absorption indicates the cooler touch feeling. Among the assessed materials, the modified Nomex® (NA1) and cotton (CZ1) fabrics had the highest heat absorption value, and thus the coolest feeling while touched. It was noticed that the modification of the basalt fabric surface did not affect the filling during the skin contact with the unmodified side.

Additional statistical analysis was performed based on the Kruskal-Wallis (K-W) test [23]. When the K-W test leads to significant results, at least one group is different from the other groups. However, the test does not identify where the difference(s) occurs. To identify the particular differences between pairs of groups, post hoc test was used. The nonparametric statistical procedure was used for comparing three groups of samples: unmodified (NM) and modified fabrics with $1 \mu \mathrm{m}$ (M1) and $5 \mu \mathrm{m}$ (M5) thick coatings. The following parameters were taken into consideration: the threshold time $t_{t 100}$ (for the contact temperature of $100^{\circ} \mathrm{C}$ ) and $t_{t 250}$ (for the contact temperature of $250^{\circ} \mathrm{C}$ ), the heat transfer coefficient $\mathrm{RHTI}_{24}$, the thermal conductivity coefficient $\lambda$, and the heat absorption coefficient $b$.

Analysis was carried out separately for fabrics coated by the aluminum and zirconium (IV) oxide coatings. The significance level of $\alpha=0.10$ was assumed. The value is associated with the null hypothesis states that there are no significant differences between the groups. Results of statistical analysis are given in Table 6.

The determined $p$-value is compared with the critical value $a$ for rejecting the null hypothesis. If $\alpha<p$, the null hypothesis must not be rejected. The results presented in Table 6 indicating the significant differences in groups are in bold and the pairs of groups are placed in brackets. It was noticed that a significant change in the threshold time value is caused by the modification with $5 \mu \mathrm{m}$ thick coating. The changes were found for parameter $\mathrm{RHTI}_{24}$ for both aluminum and zirconium coatings and parameter $t_{t 250}$ only for the aluminum coating. The remaining parameters were improved, but not as much as the above parameters.

\section{Conclusions}

The following conclusions can be drawn from the performed research.

Almost first efficiency level was reached for basalt fabric (BZ5) coated with zirconia with a thickness of $5 \mu \mathrm{m}$, and the threshold time equal to $14.9 \mathrm{~s}$ for the contact temperature equals $100^{\circ} \mathrm{C}$. None of the fabrics achieved second level of effectiveness of

Table 6. Results of statistical analysis

\begin{tabular}{|c|c|c|c|c|}
\hline \multirow{2}{*}{ Parameter } & K-W test & Post-hoc test & K-W test & Post-hoc test \\
\hline & \multicolumn{2}{|c|}{ Coating: aluminum } & \multicolumn{2}{|c|}{ Coating: zirconium (IV) oxide } \\
\hline$t_{t 100}$ & $p=0.8371$ & - & $p=0.2521$ & - \\
\hline$t_{t 250}$ & $p=0.4035$ & - & $p=0.0273$ & $\begin{array}{l}p=0.539(\mathrm{NM}, \mathrm{M} 1) \\
p=0.022(\mathrm{NM}, \mathrm{M} 5) \\
p=0.539(\mathrm{M} 1, \mathrm{M} 5)\end{array}$ \\
\hline $\mathrm{RHTI}_{24}$ & $p=0.0509$ & $\begin{array}{l}p=0.303(\mathrm{NM}, \mathrm{M} 1) \\
p=0.051(\mathrm{NM}, \mathrm{M} 5) \\
p=1.000(\mathrm{M} 1, \mathrm{M} 5)\end{array}$ & $p=0.0665$ & $\begin{array}{l}p=0.158(\mathrm{NM}, \mathrm{M} 1) \\
p=0.099(\mathrm{NM}, \mathrm{M} 5) \\
p=1.000(\mathrm{M} 1, \mathrm{M} 5)\end{array}$ \\
\hline$\lambda$ & $p=0.1133$ & - & $p=0.2019$ & - \\
\hline$b$ & $p=0.1133$ & - & $p=0.1931$ & - \\
\hline
\end{tabular}

K-W, Kruskal-Wallis. 
protection against contact heat. The threshold time was much below $15.0 \mathrm{~s}$ for the contact temperature equal to $250^{\circ} \mathrm{C}$.

The first level of protection against heat radiation was obtained for all reference and modified samples. The second level of protection efficiency was achieved for the modified fabrics: basalt (BA1, BA5), Nomex® (NA1, NA5), and cotton fabric (CA5).

Research of selected thermal comfort properties (conductivity coefficient and heat absorption coefficient) showed that the best fabric in terms of comfort properties is unmodified basalt fabric (B), for which $\lambda=38.19 \times 10^{-3} \mathrm{Wm}^{-1} \mathrm{~K}^{-1}$. An upward trend in the thermal conductivity coefficient has been observed for all modified fabrics.

Modification of the surface of Nomex® and cotton fabrics increased the coefficient $b$ determined on the unmodified side of the samples, in particular NA1 and CZ1. Thus, the unmodified side of fabrics in contact with the skin gives the highest coolest feeling, while touched.

Based on the statistical analysis, it was found that a significant change in the parameter value is caused by the modification with $5 \mu \mathrm{m}$ thick coating. Parameter $\mathrm{RHTI}_{24}$ for both aluminum and zirconium coatings and threshold time $t_{t 250}$ for the aluminum coating were improved significantly (assuming $\alpha=0.10$ ) compared with unmodified fabrics.

Samples BZ5, BZ1, NZ5, CZ5 are the best from the point of view of resistance to contact heat, while improving the coolness feeling from the unmodified side. Attention should be paid to the fact that the unmodified side of basalt fabric BZ5 and BZ1 that has direct contact with the user's skin can cause an irritation to the skin. Nomex® fabrics NA1 and NA5 are not comfortable materials to be used in garments worn every day and require an additional skin-friendly layer. Cotton fabric CZ5 is the most skin-friendly fabric.

\section{References}

[1] Mattox, D. M. (2010). Handbook of physical vapor deposition (PVD) processing. Elsevier Books (Amsterdam, Holland).

[2] Burakowski, T., Wierzchoń, T. (1998). Surface engineering of metals: Principles, equipment, technologies. CRC Press (Boca Raton, USA).

[3] Bula, K., Koprowska, J., Janukiewicz, J. (2006). Application of cathode sputtering for obtaining ultra-thin metallic coatings on textile products. Fibres and Textiles in Eastern Europe, 14, 5(59), 75-79.

[4] Korzeniewska, E., Szczęsny, A. (2018). Parasitic parameters of thin film structures created on flexible substrates in PVD process. Microelectronic Engineering, 193, 62-64.

[5] Korzeniewska, E., Duraj. A., Krawczyk. A., Murawski. $P$. (2016). Analysis of thermographic images of thin metal layers using grouping algorithms. Przeglad Elektrotechniczny, 92(12), 73-76.
[6] Deng, B., Wei, Q., Gao, W., Yan, X. (2007). Surface functionalization of nonwovens by aluminum sputter coating. Fibres and Textiles in Eastern Europe, 15, 4(63), 90-92.

[7] Chen, Y., Hsu, C., He, J. (2013). Antibacterial silver coating on poly(ethylene terephthalate) fabric by using high power impulse magnetron sputtering. Surface and Coatings Technology, 232, 868-875.

[8] Zhai, Y., Liu, X., Xiao, L. (2015). Magnetron sputtering coating of protective fabric study on influence of thermal properties. Journal of Textile Science and Technology, 1(3), 127-134.

[9] Han, H. R., Park, Y., Yun, C., Park, C. H. (2018). Heat transfer characteristics of aluminum sputtered fabrics. Journal of Engineered Fibers and Fabrics, 13(3), 37-44.

[10] Saleemi, S., Naveed, T., Riaz, T., Memon, H., Ashraf, J. A., Siyal, M. I., Xu, F., Bae, J. (2020). Surface functionalization of cotton and PC fabrics using $\mathrm{SiO} 2$ and $\mathrm{ZnO}$ nanoparticles for durable flame retardant properties. Coatings, 10(124), 1-12.

[11] Miśkiewicz, P., Frydrych, I., Pawlak, W., Cichocka, A. (2019). Modification of surface of basalt fabric on protecting against high temperatures by the method of magnetron sputtering. Autex Research Journal, 19(1), 36-43.

[12] Miśkiewicz, P., Frydrych, I., Pawlak, W. (2019). The influence of basalt fabrics modifications on their resistance to contact heat and comfort properties. International Journal of Clothing Science and Technology, 31(6), 874886.

[13] Miśkiewicz, P., Frydrych, I. Tokarska, M., Pawlak, W. (2019). Study on some thermal and electrical properties of basalt fabric modified with metal and ceramics as a result of magnetron sputtering. Polymers, 11(12), 1-15.

[14] Wei, Q. (Ed.) (2009). Surface modification of textiles. Woodhead Publishing (Sawston, UK).

[15] Web site: https://www.basaltft.com/prop/fire.htm (accessed 10 March 2020).

[16] Web site: https://www.dupont.com/products/nomex-fibers. html (accessed 10 March 2020).

[17] Web site: https://www.yulongfrtex.com/fabric/cotton-arcproof-fabric (accessed 10 March 2020).

[18] EN 407:2004. (2004). Protective gloves against thermal risks (Heat and/or Fire).

[19] ISO 12127-1:2016. (2016). Clothing for protection against heat and flame - determination of contact heat transmission through protective clothing or constituent materials - Part 1: Contact heat produced by heating cylinder.

[20] ISO 6942:2005. (2005). Protective clothing-Protection against heat and fire-Method of test: Evaluation of materials and materials assemblies when exposed to a source of radiant heat.

[21] Hes, L., Dolezal, I. (2018). Indirect measurement of moisture absorptivity of functional textile fabrics. Journal of Physics: Conference Series, 1065, 1-4.

[22] Matusiak, M. (2006). Investigation of the thermal insulation properties of multilayer textiles. Fibres and Textiles in Eastern Europe, 14, 5(59), 98-102.

[23] Corder, G. W., Foreman, D. I. (2009). Nonparametric statistics for non-statisticians: A step-by-step approach. Wiley (Hoboken, US). 